\title{
Geomagnetic storm and equatorial spread-F
}

\author{
F. Becker-Guedes ${ }^{1}$, Y. Sahai ${ }^{1}$, P. R. Fagundes ${ }^{1}$, W. L. C. Lima $^{2}$, V. G. Pillat ${ }^{1}$, J. R. Abalde ${ }^{1}$, and J. A. Bittencourt ${ }^{3}$ \\ ${ }^{1}$ Universidade do Vale do Paraiba (UNIVAP), 12244-000 Sao Jose dos Campos, SP, Brazil \\ ${ }^{2}$ Centro Universitario Luterano de Palmas (CEULP), Universidade Luterana do Brasil (ULBRA), 77054-970 Palmas, TO, \\ Brazil \\ ${ }^{3}$ Instituto Nacional de Pesquisas Espacias (INPE), 12201-970 Sao Jose dos Campos, SP, Brazil
}

Received: 14 November 2003 - Revised: 19 May 2004 - Accepted: 9 June 2004 - Published: 23 September 2004

Part of Special Issue "Equatorial and low latitude aeronomy"

\begin{abstract}
In August 2000, a new ionospheric sounding station was established at Sao Jose dos Campos $\left(23.2^{\circ} \mathrm{S}\right.$, $45.9^{\circ} \mathrm{W}$; dip latitude $17.6^{\circ} \mathrm{S}$ ), Brazil, by the University of Vale do Paraiba (UNIVAP). Another ionospheric sounding station was established at Palmas $\left(10.2^{\circ} \mathrm{S}, 48.2^{\circ} \mathrm{W}\right.$; dip latitude $5.5^{\circ} \mathrm{S}$ ), Brazil, in April 2002, by UNIVAP in collaboration with the Lutheran University Center of Palmas (CEULP), Lutheran University of Brazil (ULBRA). Both the stations are equipped with digital ionosonde of the type known as Canadian Advanced Digital Ionosonde (CADI). In order to study the effects of geomagnetic storms on equatorial spread-F, we present and discuss three case studies, two from the ionospheric sounding observations at Sao Jose dos Campos (September and November 2000) and one from the simultaneous ionospheric sounding observations at Sao Jose dos Campos and Palmas (July 2003). Salient features from these ionospheric observations are presented and discussed in this paper. It has been observed that sometimes (e.g. 4-5 November 2000) the geomagnetic storm acts as an inhibitor (high strong spread-F season), whereas at other times (e.g. 11-12 July 2003) they act as an initiator (low strong spreadF season), possibly due to corresponding changes in the quiet and disturbed drift patterns during different seasons.
\end{abstract}

Key words. Ionosphere (equatorial ionosphere; ionospheric irregularities) - Magnetospheric physics (storms and substorms)

\section{Introduction}

The response of the equatorial ionosphere during geomagnetic storms is one of the prominent issues related to space weather studies. How geomagnetic storms affect the occurrence characteristics of equatorial spread-F (plasma irregularities, with scale sizes varying from less than a meter to several hundred kilometers, associated with the nighttime equatorial ionospheric F-region) is an important aspect

Correspondence to: F. Becker-Guedes

(fabio@univap.br) related to these studies and has important implications for trans-ionospheric communications. Adverse effects of ionospheric storms on sophisticated and advanced ground-based and space-borne systems are being increasingly observed and, sometimes influence day-to-day human activity. During geomagnetic storms, electric fields in the equatorial region could be affected by two main high-latitude sources viz. the solar wind-magnetosphere dynamo (direct or prompt penetration of the magnetospheric convection electric field) (Senior and Blanc, 1984; Spiro, 1988) and the ionospheric disturbance dynamo (Joule heating at high latitudes) (Blanc and Richmond, 1980).

The class of equatorial spread-F which has been the subject of extensive experimental studies (e.g. Abdu et al., 1998; Fejer et al., 1999; Palmroth et al., 2000; Sahai et al., 2000; Whalen, 2002; Huang et al., 2002), as well as theoretical ones (e.g. Sultan, 1996; Sekar and Kelley, 1998), during the recent years, are known as trans-equatorial plasma bubbles associated with strong range spread-F and have the highest disruptive levels of trans-ionospheric communications. As pointed out by Abdu et al. (1998; see also Whalen, 2002) the spread-F in equatorial ionograms represent bottomside plasma irregularities that either could be associated, or not, with the equatorial plasma bubbles, whereas the spread-F in low-latitude ionograms are indicative of equatorial plasma bubbles or macroscopic bubbles (Whalen, 2002). The equatorial plasma bubbles are formed in the post-sunset period, at the magnetic equator, due to the Rayleigh-Taylor gravitational instability process operational on the steep upward gradient in the bottomside F-region.

The effect of geomagnetic storms on equatorial spread-F and plasma bubbles has been the subject of several investigations (e.g. Bowman, 1982; DasGupta et al., 1985; Aarons, 1991; Sahai et al., 1998, 2004; Fejer et al., 1999; Palmroth et al., 2000; Huang et al., 2001; Whalen, 2002). It appears that there is a general consensus that geomagnetic activity tends to suppress the generation of equatorial spread-F in the post-sunset (pre-midnight) period (e.g. Bowman, 1982; Buonsanto, 1999; Palmroth et al., 2000; Kelley et al., 2000), whereas the possibility of observing equatorial spread-F 


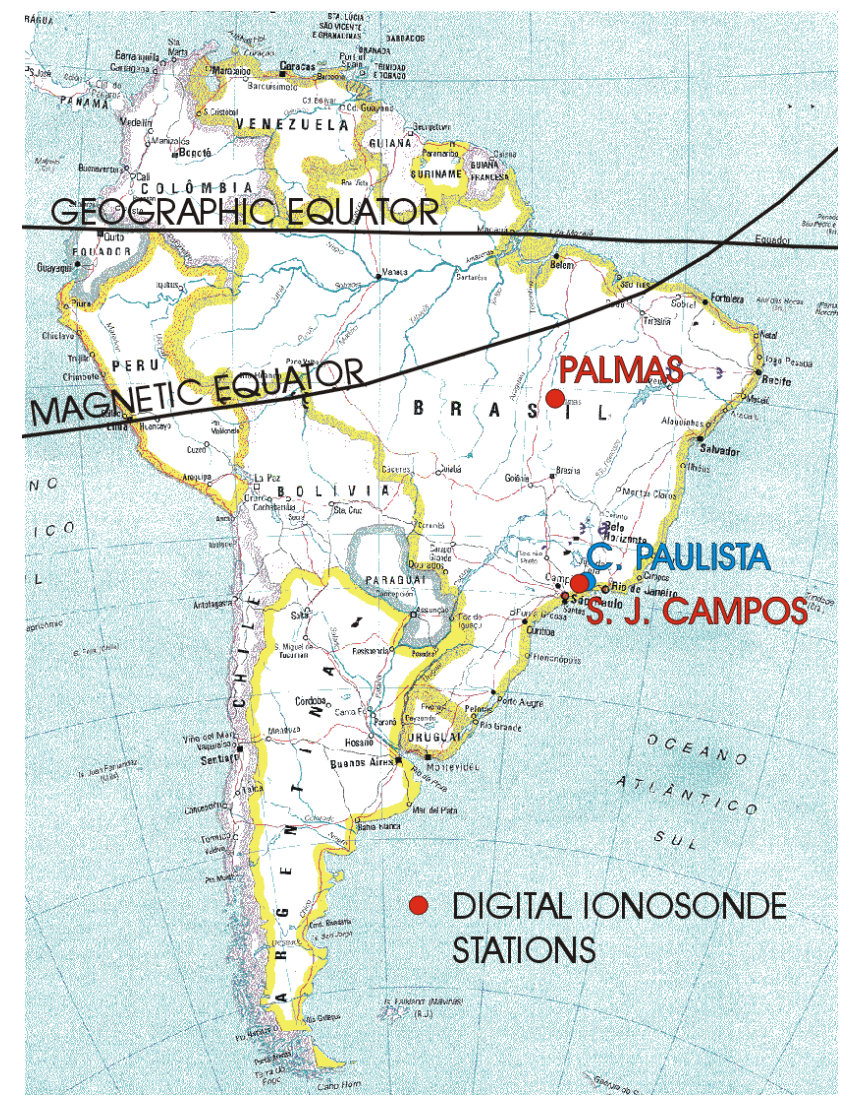

Fig. 1. A map showing the locations of the ionospheric sounding stations Palmas and Sao Jose dos Campos. Also, the location of Cachoeira Paulista indicated in the paper is shown.

(hereafter referred as ESF) during the post-midnight period increases with geomagnetic activity (e.g. Bowman, 1982; Fejer et al., 1999; Palmroth et al., 2000). However, using the ionospheric plasma density measurements on board the Defense Meteorological Satellite Program (DMSP) flights, orbiting at an altitude of about $800 \mathrm{~km}$, Huang et al. (2001) have reported that, contrary to the general belief, equatorial plasma bubbles (strong spread-F, hereafter referred as EPBs) develop in the evening sector during the early stages of high geomagnetic activity periods and are later suppressed. Also, using a large data base of the OI 630-nm nightglow emission all-sky images from Cachoeira Paulista $\left(22^{\circ} \mathrm{S}, 45^{\circ} \mathrm{W}\right)$, a low-latitude station in Brazil, Sahai et al. (1998, 2004) have presented many examples of the observations of EPBs in both evening (continuing throughout the night) and morning sectors during geomagnetic disturbances. Therefore, it should be pointed out that during geomagnetic disturbances the occurrence of EPBs is not limited to the morning sector only. Now there are increasing evidences that during geomagnetic disturbances EPBs are observed during the evening sector as well. Whalen (2002) has reported that the probability of EPB occurrence is a quantitative function of $K_{p}$ and season, with suppression that can be represented as a linear function of $K_{p}$ during the equinox (E) (March, April,
September and October) and summer (D) (December solstice - November to February) months in the western South American sector, and by contrast no dependence on $K_{p}$ during the winter (J) (June solstice - May to August) months. However, the occurrence of EBPs during the $\mathbf{J}$ months is very rare in the Brazilian sector (e.g. Tsunoda, 1985; Abdu et al., 1992; Sahai et al., 1998).

In the Brazilian sector it is now known that there are distinct strong spread-F (EPBs) seasons (Sahai et al., 1994, 1998, 2004; Abdu et al., 1998), with high occurrence during the $\mathrm{D}$ months, low occurrence during the $\mathrm{J}$ months, and the equinox E months showing transition characteristics from high to low and vice versa. The observed seasonal dependence of the EPBs in the Brazilian sector is associated with the magnetic declination control (about $20^{\circ} \mathrm{W}$ ) (Tsunoda, 1985; Maruyama, 1988; Abdu et al., 1992).

In August 2000, a new ionospheric sounding station was established at Sao Jose dos Campos $\left(23.2^{\circ} \mathrm{S}, 45.9^{\circ} \mathrm{W}\right.$; dip latitude $17.6^{\circ} \mathrm{S}$; a low-latitude station hereafter referred as SJC), Brazil, by the University of Vale do Paraiba (UNIVAP). Another ionospheric sounding station was established at Palmas $\left(10.2^{\circ} \mathrm{S}, 48.2^{\circ} \mathrm{W}\right.$; dip latitude $5.5^{\circ} \mathrm{S}$, a near dip equator station hereafter referred as PAL), Brazil, in April 2002, by UNIVAP in collaboration with the Lutheran University Center of Palmas (CEULP), Lutheran University of Brazil (ULBRA). Both stations are equipped with digital ionosonde of the type known as Canadian Advanced Digital Ionosonde (CADI) (Grant et al., 1995; Abalde et al., 2001).

In this paper, we present and discuss three case studies related to ESF occurrence/suppression during geomagnetic disturbances from ionospheric sounding observations in three different seasons, two from the observations at SJC (September 2000 - transition from low to high occurrence rates of EPBs-E month - and November 2000 - high occurrence rates of EPBs-D month) and one from the simultaneous ionospheric sounding observations at SJC and PAL (July 2003 - low occurrence rates of EPBs-J month).

\section{Results and discussion}

The locations of the ionospheric sounding stations, SJC and PAL, are shown in Fig. 1. The two stations are separated by about $1460 \mathrm{~km}$, with PAL close to the magnetic equator and SJC under the crest of the equatorial ionospheric anomaly (in the equatorial and low-latitude regions, the Flayer electron density falls to a minimum over the magnetic equator and passes through maxima at dip latitudes $10^{\circ}-20^{\circ}$ north and south of the magnetic equator). The universal time (UT) for both stations is $3 \mathrm{~h}$ ahead of the local time (LT). In this study we present the ionospheric sounding observations obtained at SJC during the periods 14 September to 19 September 2000 (transition from low to high occurrence rates of EPBs-E month) and 2 November to 7 November 2000 (high occurrence rates of EPBs-D month), at both SJC and PAL during the period 10 to 13 July 2003 (low occurrence rates of EPBs-J month). All three periods used in the present 
Table 1. Details of magnetic activity.

\begin{tabular}{|c|c|c|c|c|}
\hline Date & $\begin{array}{l}3-\mathrm{H} K_{p} \\
\text { between 06:00 } \\
\text { and 06:00 (LT) }\end{array}$ & $\begin{array}{l}\text { Min. } D_{s t} \\
\text { between 06:00 } \\
\text { and 06:00 (LT) }\end{array}$ & $\operatorname{SSC}(\mathrm{LT})$ & Remarks \\
\hline 14-15 Sept. $2000(Q)$ & $1-, 1-, 1,1,1,0+, 3-, 1-$ & 14 Sept.; 06:00; $-25 \gamma$ & None & No spread-F at SJC* \\
\hline 15-16 Sept. $2000(\mathrm{Q})^{* *}$ & $1,1,2-, 3+, 5,4-, 3,3-$ & 16 Sept.; 00:00; $-39 \gamma$ & None & No spread-F at SJC* \\
\hline 16-17 Sept. 2000 (D) & $3+, 3,4-, 4+, 6+, 5-, 4,2+$ & 16 Sept.; $21: 00 ;-68 \gamma$ & None & Range spread-F at SJC* \\
\hline 17-18 Sept. 2000 (D) & $3,4,5-, 5+, 8+, 8-, 6-, 5$ & 17 Sept.; $21: 00 ;-201 \gamma$ & 17 Sept.; 11:28 & Range spread-F at SJC* \\
\hline 18-19 Sept. 2000 (Q) & $6,6,6,3,3,3,3,3$ & 18 Sept.; 06:00; $-108 \gamma$ & 18 Sept.; 11:43 & No spread-F at SJC* \\
\hline 01-02 Nov. 2000 (Q) & $0+, 1,1,1+, 2+, 3-, 1-, 0+$ & 01 Nov.; 22:00; $-21 \gamma$ & None & Range spread-F at SJC* \\
\hline 02-03 Nov. 2000 (Q) & $0+, 1,1-, 1-, 1-, 0,0,0+$ & 02 Nov.; $11: 00 ;-18 \gamma$ & None & Range spread-F at SJC* \\
\hline 03-04 Nov. $2000(\mathrm{Q})^{* *}$ & $0+, 1,1,2,2,3,5,4$ & 04 Nov.; 06:00; $-47 \gamma$ & 03 Nov.; 23:23 & No spread-F at SJC* \\
\hline 04-05 Nov. $2000(\mathrm{Q})^{* *}$ & $4,4-, 4,4-, 4-, 4-, 3,2$ & 04 Nov.; 07:00; $-50 \gamma$ & None & No spread-F at SJC* \\
\hline 05-06 Nov. $2000(\mathrm{Q})^{* *}$ & $1-, 3,3+, 3+, 3+, 3+, 4-, 4$ & 05 Nov.; $21: 00 ;-46 \gamma$ & None & No spread-F at SJC* \\
\hline 06-07 Nov. 2000 (D) & $5,5+, 6-, 7,6-, 6,7-, 5+$ & 06 Nov.; 19:00; $-159 \gamma$ & 06 Nov.; 06:47 & No spread-F at SJC* \\
\hline 09-10 July 2003 (Q) & $1-, 1,0+, 2-, 1+, 1+, 1+, 2$ & 09 July; 06:00; $21 \gamma$ & None & Freq. Spread-F at PAL \\
\hline $10-11$ July $2003(\mathrm{Q})^{* *}$ & $2,3-, 1,1+, 3-, 3-, 4+, 6$ & 11 July; 06:00; $-26 \gamma$ & None & Freq. Spread-F at PAL \\
\hline 11-12 July 2003 (D) & $5,5+, 5+, 6-, 6-, 6,7-, 5+$ & 12 July; 03:00; $-81 \gamma$ & None & Range spread-F at PAL/SJC \\
\hline $12-13$ July $2003(\mathrm{Q})^{* *}$ & $3+, 4,3,4-, 3+, 3,3-, 3+$ & 12 July; 07:00; $-46 \gamma$ & None & Freq. spread-F at PAL/SJC \\
\hline
\end{tabular}

* Only CADI at SJC in operation.

** With some magnetic activity.

study include geomagnetically quiet, disturbed and recovery phases. The observed ionospheric parameters ( $\mathrm{h}^{\prime} \mathrm{F}$ and $\left.f o \mathrm{~F} 2\right)$ presented in this study from both stations, SJC and PAL, are values recorded every $15 \mathrm{~min}$ (ionospheric sounding is carried out every $5 \mathrm{~min}$ ). Table 1 presents details of magnetic activity during the three periods studied. To classify a night with magnetic disturbance or storm, we have used the criterion of $K_{p} \geq 4$ for at least three 3-h periods between 15:00 to 06:00 LT. Q in Table 1 indicates quiet conditions and $\mathrm{Q}^{* *}$ indicates that some geomagnetic activity has been associated with this night.

2.1 Spread-F observations during a transition from low to high occurrence rates of EPBs (E month)

Figure 2a shows the $K_{p}$ (3-h; source website - http://ftp. gwdg.de/pub/geophys/kp-ap/tab/) , $D_{s t}$ (hourly; source website - http://swdcdb.kugi.kyoto-u.ac.jp/wdc/Sec3.html) and $A E$ (every $15 \mathrm{~min}$ or less; source website $-\mathrm{http} / / / \mathrm{swdcdb}$. kugi.kyoto-u.ac.jp/wdc/Sec3.html) magnetic indices during the period 14-19 September 2000. During this period there were 2 storm-time sudden commencements (SSCs) occurring at 14:28 UT (11:28 LT) on 17 September and 14:43 UT (11:43 LT) on 18 September (SSC-source website - http://ftp.gwdg.de/pub/geophys/kp-ap/tab/).

Figure 2a also shows the variations of $h^{\prime} \mathrm{F}$ (minimum virtual height of F-region), foF2 (corresponding to F-region peak electron density) and spread-F (range, frequency or mixed), if present, observed at SJC during the period 1419 September 2000. The local nighttime periods (18:0006:00 LT) are indicated by the hatched portions in Fig. 2a.
As pointed out by VanZandt et al. (1971), the most direct and easily observable effects of vertical electromagnetic drift during a geomagnetic storm are changes in the F-region height and presented here by $\mathrm{h}^{\prime} \mathrm{F}$. Also, during a geomagnetic storm, the F-region electron density ( $f o \mathrm{~F} 2)$ can both increase (positive ionospheric storm or phase) and decrease (negative ionospheric storm or phase) compared with the quiet time values (e.g. Danilov and Morozova, 1985). The positive ionospheric storm effects at equatorial and low latitudes are associated with electrodynamic lifting of the F-region, whereas the negative ionospheric storm effects are related to the changes in neutral composition due to travelling atmospheric disturbances from a high-latitude region (e.g. Prolss and Najita, 1975).

A perusal of Fig. 2a indicates that 14 and 15 September are geomagnetically quiet, except for some magnetic activity around the end of 15 September (between 21:00 to 24:00 UT). The 16 to 18 September period is geomagnetically disturbed, but the recovery phase starts on 18 September again with some magnetic activity on 19 September (between 12:00 to 17:00 UT). Since we are investigating the effects of geomagnetic storms on equatorial spread-F, we shall concentrate our studies on the nighttime ionospheric sounding observations, mostly between 18:00 LT (21:00 UT) to 06:00 LT (09:00 UT). Figure 2a shows the presence of range spread-F (indicating the presence of EBPs, as mentioned earlier) only on the nights of 16-17 and 17-18 September. Both nights are geomagnetically disturbed (Table 1).

During the post-sunset period, on both 16 and 17 September, the $h^{\prime} F$ variations show an uplift of about $60 \mathrm{~km}$ 


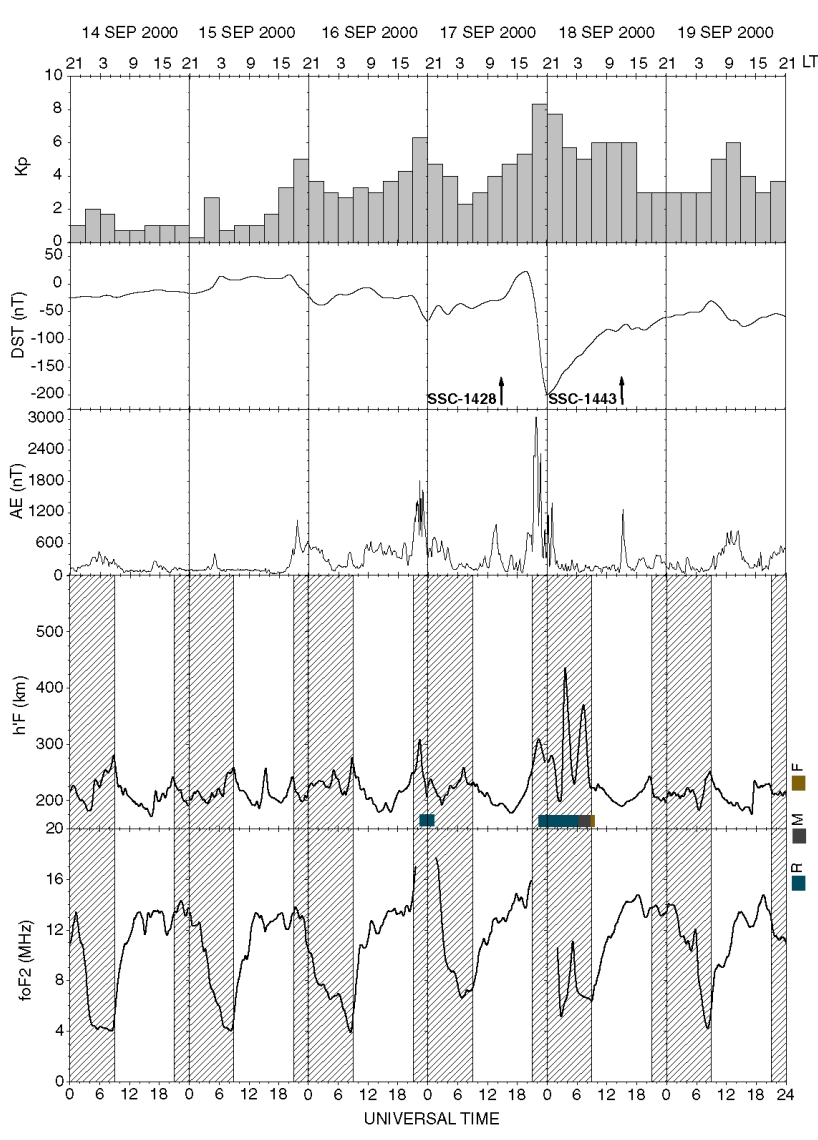

Fig. 2a. The variations of the $K_{p}, D_{s t}$ and $A E$ geomagnetic indices and ionospheric parameters $\mathrm{h}^{\prime} \mathrm{F}$ and $f o \mathrm{~F} 2$ observed at Sao Jose dos Campos during the period of 14 to 19 September 2000. The periods of spread-F (range R, mixed M and frequency F) are shown by horizontal bars.

(compared with the quiet days 14 and 15 September) at about 19:00 LT, followed by the generation of range spreadF. The F-region uplift phase on both the late evenings (16 and 17 September) occurs simultaneously with a large increase in the $A E$ index (Fig. 2a) and is possibly associated with the prompt penetration of magnetospheric convective electric fields to low latitudes. Also, the variations of $f o \mathrm{~F} 2$ on the night of 16-17 September show an unusual increase (positive phase) accompanying the $\mathrm{h}^{\prime} \mathrm{F}$ uplift and the positive phase continues throughout the night, as evident from comparison with the earlier quiet nights. As mentioned earlier, the positive phase is also associated with the eletrodynamic lifting of the F-region. During the night of 17-18 September, after the initial uplifting of the F-region around 19:00 $\mathrm{LT}$, the variations in $\mathrm{h}^{\prime} \mathrm{F}$ show strong oscillations with a period of about $3 \mathrm{~h}$. Figure $2 \mathrm{~b}$ shows the variations of virtual heights at fixed frequencies on 17 and 18 September, showing large increases in the F-region heights during the night of 17-18 September, after the SSC at 14:28 UT on 17 September and a large enhancement of ring current $\left(\left|D_{s t}\right|=200 \mathrm{nT}\right)$ around midnight (UT) on 17-18 September. Also, the variations in $f \circ \mathrm{F} 2$ show first a positive phase (around the uplifting time) followed by oscillatory behavior. The absence of short

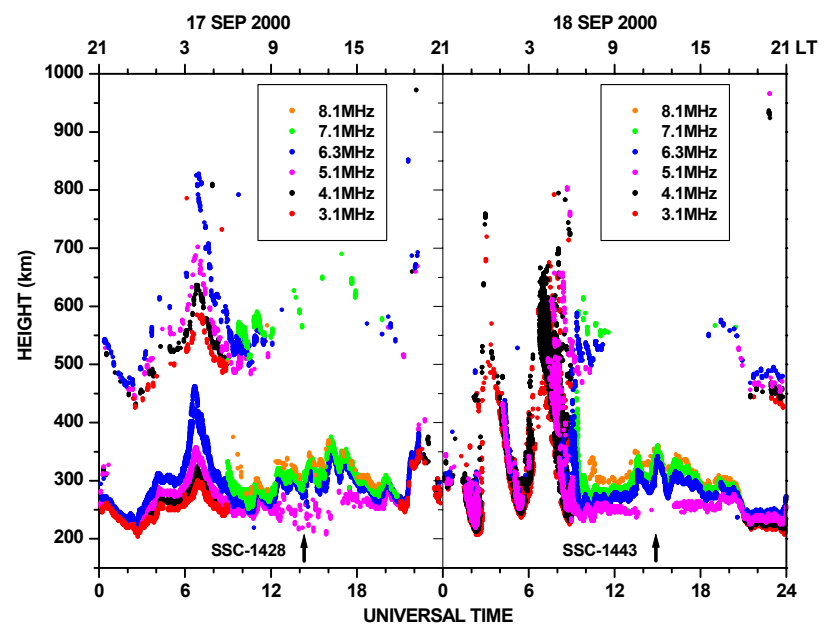

Fig. 2b. The variations of vertical heights at different fixed frequencies observed at Sao Jose dos Campos on 17 and 18 September 2000 .

periods of $f_{o} \mathrm{~F} 2$ values on both $16-17$ and 17-18 September is due to the presence of strong spread-F on the ionograms. It appears that the oscillatory part of both the $\mathrm{h}^{\prime} \mathrm{F}$ and $f \circ \mathrm{F} 2$ variations, on the night of 17-18 September, may be related to the Joule heating at high latitudes that may drive traveling atmospheric disturbances (TADs) and result in changes in the neutral compositions.

It is evident from the present data set from September 2000 (transition from low to high occurrence rates of EPBsE month) that the geomagnetic disturbances have, in some way, helped in the initiation/generation process of EPBs.

\subsection{Spread-F observations during high occurrence rates of EPBs (D month)}

Figure 3 shows the $K_{p}$ (3-h; source website - http:// ftp.gwdg.de/pub/geophys/kp-ap/tab/), $D_{s t}$ (hourly; source website - http://swdcdb.kugi.kyoto-u.ac.jp/wdc/Sec3.html) and $A E$ (every $15 \mathrm{~min}$ or less; source website - http:// swdcdb.kugi.kyoto-u.ac.jp/wdc/Sec3.html) magnetic indices during the period 2-7 November 2000. During this period there were 3 storm-time sudden commencements (SSCs) occurring at 02:23 UT (23:23 LT on 3 November) on 4 November, 09:47 UT (06:47 LT) on 6 November and 18:16 UT (15:16 LT) on 7 November (SSC-source website - http://ftp.gwdg.de/pub/geophys/kp-ap/tab/).

Figure 3 indicates that, in general, the period between about 06:00 UT on 4 November, to about 12:00 UT on 7 November, is geomagnetically disturbed. Table 1 shows that the nights of 1-2 and 2-3 November are quiet, 3-4, 45 and 5-6 November have some magnetic activity, whereas 6-7 November is magnetically disturbed. Figure 3 also shows the variations of $\mathrm{h}^{\prime} \mathrm{F}, f o \mathrm{~F} 2$ and spread-F, if present, observed at SJC during the period 2-7 November 2000. During this period, it is observed that range spread-F is present only on the quiet nights of 1-2 and 2-3 November. On the 


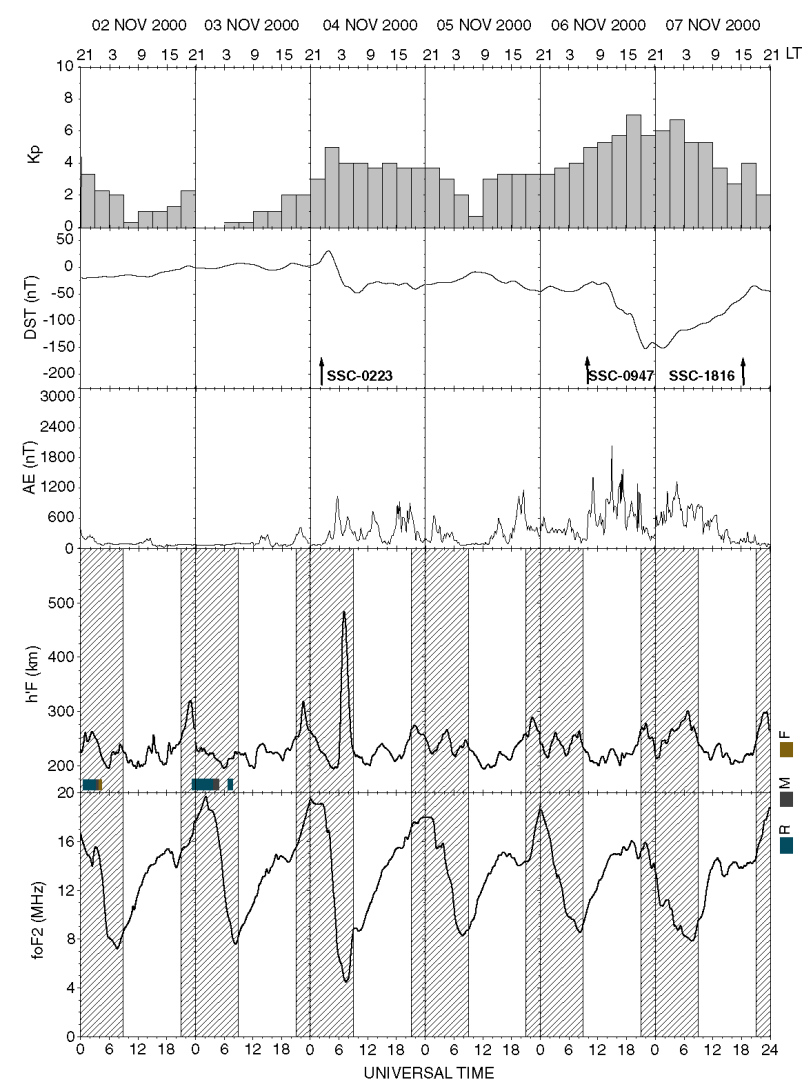

Fig. 3. Same as Fig. 2a, except for the period of 2 to 7 November 2000 .

night of 4-5 November, although the SSC was observed only at 23:23 LT, no spread-F was observed at SJC. This could be possibly due to the day-to-day variability in the generation and evolution of equatorial spread-F. However, after the $\mathrm{SSC}, \mathrm{h}^{\prime} \mathrm{F}$ shows a rapid rise to about $500 \mathrm{~km}\left(\Delta \mathrm{h}^{\prime} \mathrm{F}\right.$ of about $300 \mathrm{~km}$ ) at about 04:00 LT. During the uplift phase of $h^{\prime} F$, $f o \mathrm{~F} 2$ shows a strong negative phase and then recovers close to the normal $f o \mathrm{~F} 2$ values. The more interesting part of the data presented from the November ionospheric observations indicates the absence of spread-F at SJC between the nights of 45, 5-6 and 6-7 November, during the period of geomagnetic disturbances (Fig. 3), as mentioned earlier. Range spread$\mathrm{F}$ is observed again only on the night of 7-8 November at about 22:30 LT (not covered in Fig. 3) and then the following several quiet nights show the presence of range spread-F, which is normal for this month. During the disturbed period, foF2, in general, shows negative phase (the effect is much stronger following the SSC on 6 November) compared with the quiet days ( 2 and 3 November), possibly associated with the neutral compositional changes related to Joule heating at high latitudes and associated equatorward neutral winds. As pointed out by Fejer and Scherliess (1995), in the post-sunset period at Jicamarca, Peru, prompt penetrating electric fields enhance the vertical $\boldsymbol{E} \times \boldsymbol{B}$ plasma drift, whereas ionospheric disturbance dynamo electric fields reduce the upward uplifting.

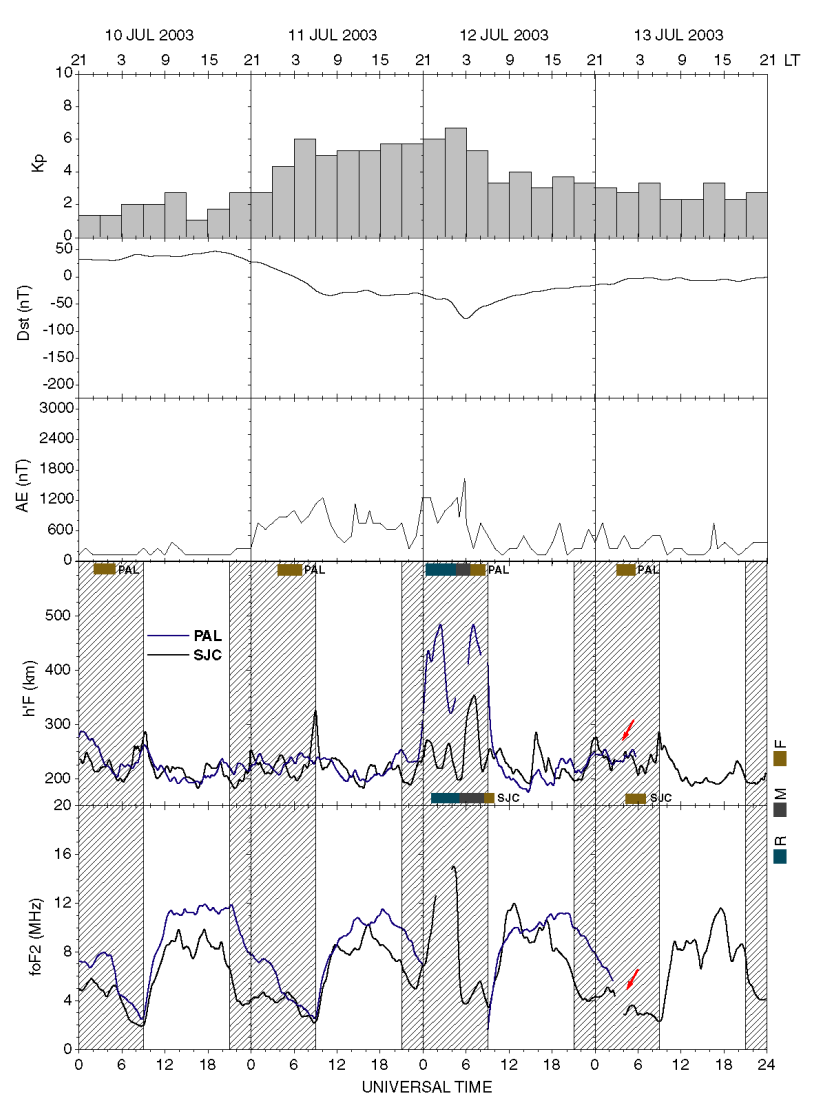

Fig. 4. Same as Fig. 2a, except for the period of 10 to 13 July 2003 and with the ionospheric parameters $\mathrm{h}^{\prime} \mathrm{F}$ and $f o \mathrm{~F} 2$ observed at Palmas. The red arrows indicate the period when strong sporadic $\mathrm{E}$ at SJC did not permit scalings of the ionograms.

It is evident from the present data set from November 2000 (high occurrence rates of EPBs-D month) that the geomagnetic disturbances have, in some way, helped in the suppression of EPBs.

\subsection{Spread-F observations during low occurrence rates of EPBs (J month)}

Figure 4 shows the $K_{p}$ (3-h; source website - http://ftp. gwdg.de/pub/geophys/kp-ap/tab/), $D_{s t}$ (hourly; source website - http://swdcdb.kugi.kyoto-u.ac.jp/wdc/Sec3.html) and $A E$ (every hour; at present, 1-min values of the $A E$ index are not available; source website - http://swdedb.kugi.kyoto-u. ac.jp/wdc/Sec3.html) magnetic indices during the period 10 13 July 2003. During this period no SSC was observed. Figure 4 shows that 11 and 12 July are geomagnetically disturbed days, with 10 July being quiet and 13 July in the recovery phase.

During this period studied, ionospheric sounding observations from both the stations PAL and SJC were available for most of the period (no observations from PAL are available after 06:00 UT on 13 July due to an instrumental problem). Figure 4 also shows the variations of $\mathrm{h}^{\prime} \mathrm{F}, f o \mathrm{~F} 2$ and spread-F, if present, observed at PAL (blue) and SJC (black) during the 


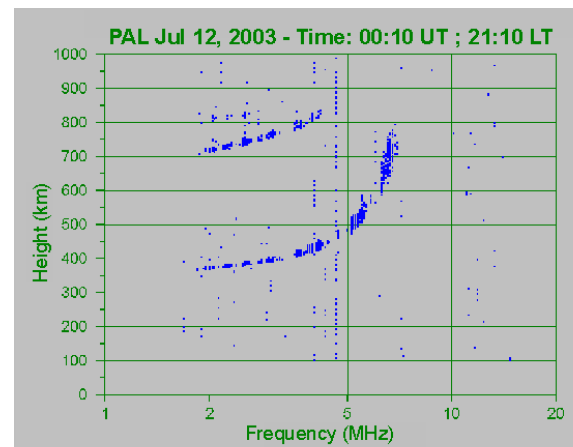

(a)

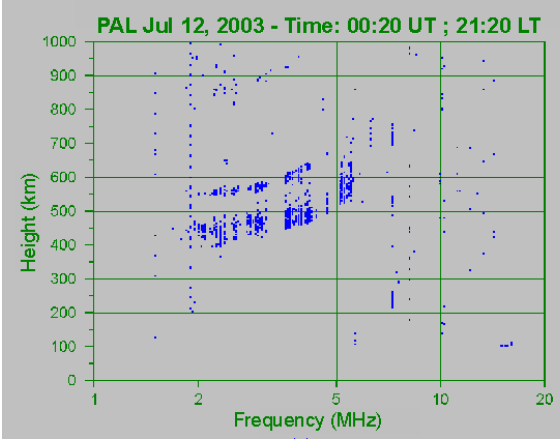

(c)

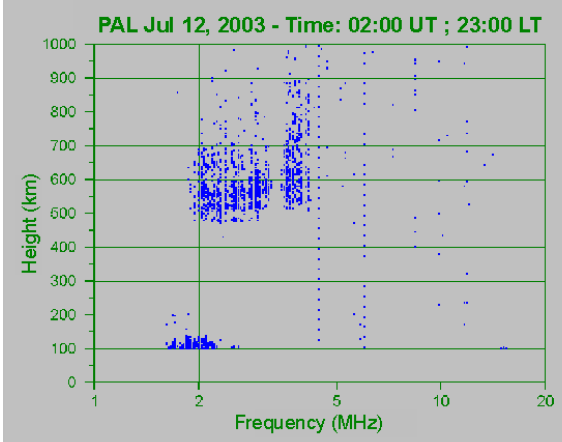

(e)

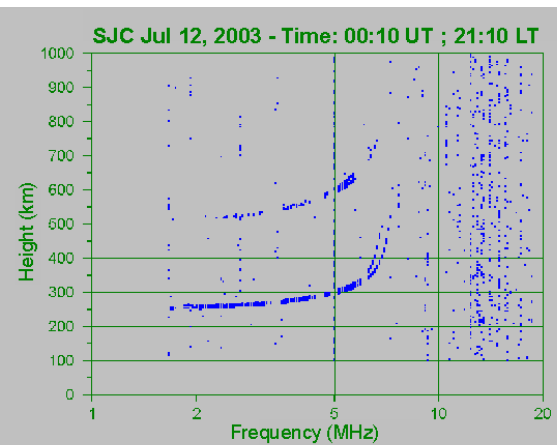

(b)

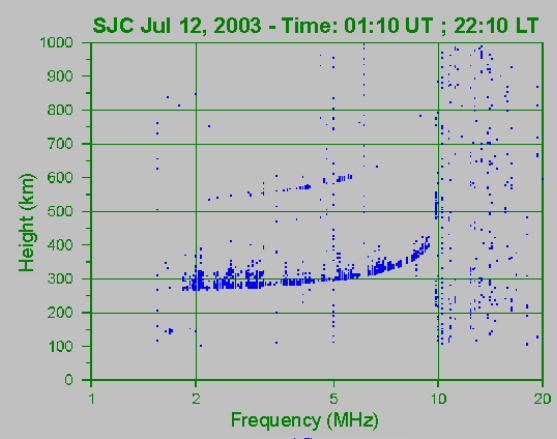

(d)

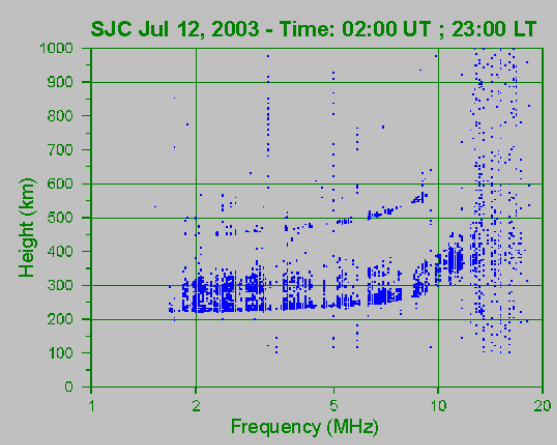

(f)

Fig. 5. Examples of ionograms obtained at Palmas and Sao Jose dos Campos on the night of 11-12 July 2003.

period 10-13 July 2003. On the quiet nights of 9-10 and 1011 July and again, during the recovery phase night of 12-13 July, frequency spread-F is observed at PAL. On the geomagnetically disturbed night of 11-12 July, it is observed that $\mathrm{h}^{\prime} \mathrm{F}$ starts to rise quickly at about 20:00 LT at PAL, attaining an altitude of about $430 \mathrm{~km}\left(\Delta \mathrm{h}^{\prime} \mathrm{F}\right.$ of about $\left.200 \mathrm{~km}\right)$ by about 22:00 LT. This is possibly associated with prompt penetration of magnetospheric convective electric fields to the equatorial region and, by 21:15 LT, range spread-F starts during the uplift phase at PAL. However, the large variations in $\mathrm{h}^{\prime} \mathrm{F}$ observed at PAL after the initial fast uplift could be due to both the prompt penetration of magnetospheric convective electric fields as well as the disturbance dynamo effect. Figure 4 shows that the time variations of the $\mathrm{h}^{\prime} \mathrm{F}$ at PAL and SJC, on the night of 11-12 July, during the geomagnetic disturbed conditions, are fairly different. Figure 5(a, c and e) shows the evolution of spread-F at PAL on this night. Thereafter, spread-F continues until the early morning hours at PAL. The
spread-F on ionograms at PAL is strong and does not permit scaling of $f o \mathrm{~F} 2$ at PAL on this night between 21:15 to 06:00 LT. Also, the altitude variations of $h^{\prime} f$ presented from PAL on the night of 11-12 July are the best estimates considering the strong spread-F on the ionograms. During the short periods, between 01:30 LT to 03:15 LT (due to strong sporadic $\mathrm{E}$ and spread-F) and between 05:00 LT to 06:00 (due to spread-F), on this night (Fig. 4) even scalings of $h^{\prime} F$ values have not beeen possible. The ionospheric sounding observations at SJC on the night of 11-12 July (Fig. 4) show a strong increase in $f o \mathrm{~F} 2$ during the uplift phase at PAL. This increase is possibly associated with the strengthening of the equatorial ionospheric anomaly (during the unusual $\boldsymbol{E} \times \boldsymbol{B}$ uplift in the equatorial region, field-aligned diffusion enhance electron densities at low latitudes). After about an hour from the onset of spread-F at PAL, spread-F at SJC is observed (Fig. 4). Figure 5 (b, $d$ and f) shows the evolution of spread$\mathrm{F}$ at SJC on the night of 11-12 July. The variations of $h^{\prime} \mathrm{F}$ at 


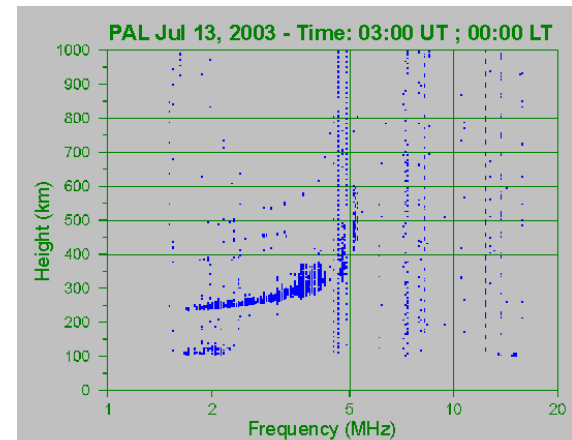

(a)

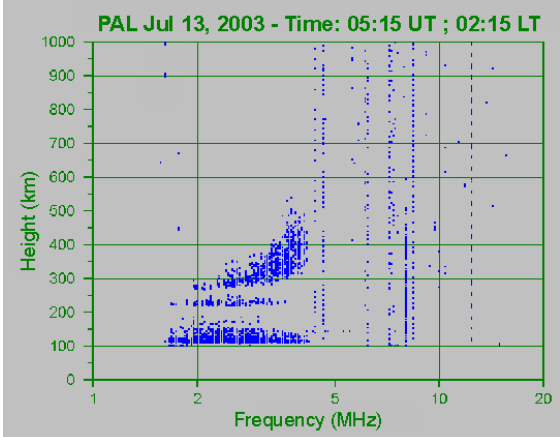

(c)

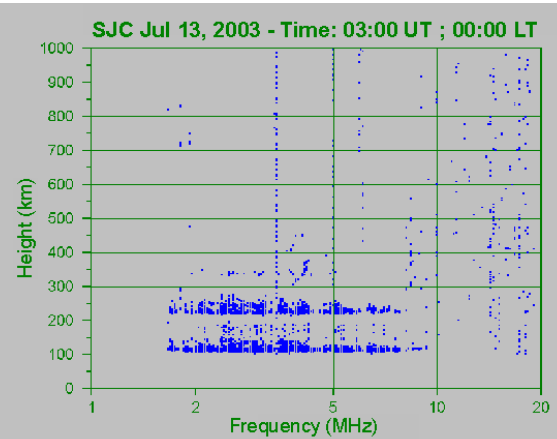

(b)

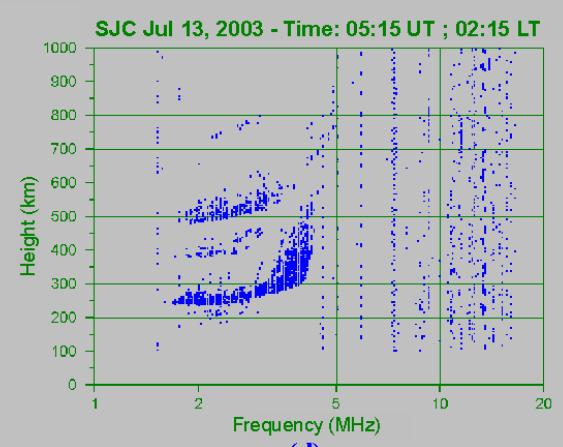

(d)

Fig. 6. Examples of ionograms obtained at Palmas and Sao Jose dos Campos on the night of 12-13 July 2003.

SJC on this disturbed night show an oscillatory nature with periods of about $3 \mathrm{~h}$, possibly associated with the traveling atmospheric disturbances (TADs) from the high-latitude region.

It should be mentioned that on the night of 12-13 July, during the geomagnetic storm recovery phase, no range spread$\mathrm{F}$ was observed. However, on this night, both PAL and SJC show the presence of frequency spread-F, first at PAL and then later at SJC (Fig. 4). The frequency spread-F is associated with the bottomside sinusoidal irregularities in the equatorial F-region (Valladares et al., 1983). However, more interesting observations on the night of 12-13 July relate to the development of the sporadic E-layer at both stations, SJC and PAL. Although the sporadic E-layer is not the theme of this study, it is worth mentioning the way the sporadic E-layer developed at both stations. On this night, between 18:30 to 02:15 LT, the sporadic E-layer was observed at SJC. However, during the period of 00:00 to 01:10 LT, sporadic E at SJC was so strong that no F-region trace were observed (shown by red arrows in Fig. 4). The sporadic Elayer was observed later at PAL between 21:15 to 02:30 LT. Strong sporadic E, inhibiting the appearance of the F-layer traces on ionograms was observed at PAL only for a short spell between 01:50 to 02:00 LT. Figure 6 shows a few ionograms from both PAL and SJC on this night. It appears that the sporadic E-layer first developed at the low-latitude region and then extended to the equatorial region. Batista and Abdu (1977) have reported magnetic storm associated delayed sporadic E enhancements due to charged particle pre- cipitation in the Brazilian geomagnetic anomaly region. The present obsevations are from the same region and indicate the possible expansion of the sporadic E-layer from low latitude to the equatorial region with time. A detailed study of the characteristics of the sporadic E-layer, including this night, will be the subject of another paper.

It is evident from the present data set from July 2003 (low occurrence rates of EPBs-J month) that the geomagnetic disturbances have, in some way, helped in the initiation/generation process of EPBs. The 3 case studies from 3 different seasons in the present investigations indicate the geomagnetic control of the generation/suppression of spreadF during different seasons, possibly due to corresponding changes in the quiet and disturbed drift patterns (e.g. Fejer et al., 1999). However, it is felt that more case studies during geomagnetic disturbed periods, with simultaneous equatorial and low-latitude ionospheric sounding and thermospheric wind observations, will be important for the understanding of high-latitude and low-latitude coupling and for equatorial spread-F studies.

\subsection{Conclusions}

In the present investigations we have presented three case studies from three different seasons using ionospheric sounding observations from equatorial and low-latitude stations in the Brazilian sector. The main results are as follows.

1. During the month of September 2000 (equinox (transition from low to high occurrence rates of EPBs) 
E month), range spread-F was observed only on two out of six nights studied from the observations at Sao Jose dos Campos, a low-latitude station. It should be pointed out that both nights with range spread-F were geomagnetically disturbed.

2. During the month of November 2000 (seven nights studied during the summer (high occurrence rates of EPBs) D month of Southern Hemisphere), no range spreadF was observed from the observations at Sao Jose dos Campos, on the four geomagnetically disturbed nights. It should be mentioned that range spread-F was observed on the two initial quiet nights. However, on one quiet night no range spread-F was observed, possibly related to the day-to-day variability of the equatorial plasma bubble development. We do not have observations available from an equatorial station in this sector on this night to check if the range spread-F was present in that region (11-12 July).

3. During the month of July 2003 (four nights studied during the winter (low occurrence rates of EPBs-J month of Southern Hemisphere), simultaneous observations from Palmas (a near equatorial station) and Sao Jose dos Campos show the presence of range spread-F at both the stations only on one night which was geomagnetically disturbed.

4. From the present investigations it appears that possibly during the low equatorial plasma bubbles (EPBs) occurrence season (winter) and transition season (equinox), geomagnetic activity in some way helps in the initiation/generation initiation process of EPBs, whereas during the normal high EPBs season (summer) it acts as inhibitor. Why this happens warrants further investigations using more case studies from the different seasons.

Acknowledgements. The work was partially supported by funds from FAPESP, SP, Brazil, through process numbers 1998/09892-0, 2002/01631-5 and 2002/12427-4.

Topical Editor M. Lester thanks M. Palmroth for her help in evaluating this paper.

\section{References}

Aarons, J.: The role of the ring current in the generation or inhibition of equatorial F-layer irregularities during magnetic storms, Radio Sci., 26, 1131-1149, 1991.

Abalde, J. R., Fagundes, P. R., Bittencourt, J. A., and Sahai, Y.: Observations of equatorial F-region plasma bubbles using simultaneous OI $777.4 \mathrm{~nm}$ and OI $630.0 \mathrm{~nm}$ imaging: New results, J. Geophys. Res., 106, 30 331-30 336, 2001.

Abdu, M. A., Batista, I. S., and Sobral, J. H. A.: A new aspect of magnetic declination control of equatorial spread-F and F-region dynamo, J. Geophys. Res., 97, 14 879-14 904, 1992.

Abdu, M. A., Sobral, J. H. A., Batista, I. S., Rios, V. H., and Medina, C.: Equatorial spread-F occurrences statistics in the American longitudes: Diurnal, seasonal and solar cycle variations, Adv. Space. Res., 22, 851-854, 1998.
Batista, I. S. and Abdu, M. A.: Magnetic storm associated delayed sporadic E enhancements in the Brazilian Geomagnetic anomaly, J. Geophys. Res., 82, 4777-4783, 1977.

Blanc, M. and Richmond, A. D.: The ionospheric disturbance dynamo, J. Geophys. Res., 85, 1669-1686, 1980.

Bowman, G. G.: Spread-F occurrence in mid- and low-latitude regions related to various levels of geomagnetic activity, J. Atmos. Terr. Phys., 44, 585-589, 1982.

Buonsanto, M. J.: Ionospheric storms - A review, Space Sci. Rev., 88, 563-601, 1999.

Danilov, A. D. and Morozova, L. D.: Ionospheric storms in the $\mathrm{F}_{2}$ region, Morphology and Physics (Review), Geomag. Aeron., 25, 593-605, 1985.

DasGupta, A., Maitra, A., and Das, S. K.: Postmidnight equatorial scintillation activity in relation to geomagnetic disturbances, J. Atmos. Terr. Phys., 47, 911-916, 1985.

Fejer, B. G. and Scherliess, L.: Time dependent response of equatorial ionospheric fields to magnetospheric disturbances, Geophys. Res. Lett., 22, 851-854, 1995.

Fejer, B. G., Scherliess, L., and de Paula, E. R.: Effects of the vertical plasma drift velocity on the generation of equatorial spread-F, J. Geophys. Res., 104, 19 859-19869, 1999.

Grant, I. F., MacDougall, J. W., Ruohoniemi, J. M., Bristow, W. A., Sofko, G. J., Koehler, J. A., Danskin, D., and Andre, D.: Comparison of plasma flow velocities determined by the ionosonde Doppler drift technique, SuperDARN radars, and patch motion, Radio Sci., 30, 1537-1549, 1995.

Huang, C. Y., Burke, W. J., Machuzak, J. S., Gentile, L. C., and Sultan, P. J.: DMSP observations of equatorial plasma bubbles in the topside ionosphere near solar maximum, J. Geophys. Res., 106, 8131-8142, 2001

Huang, C. Y., Burke, W. J., Machuzak, J. S., Gentile, L. C., and Sultan, P. J.: Equatorial plasma bubbles observed by DMSP satellites during a full solar cycle: Toward a global climatology, J. Geophys. Res., 107, 1434, doi:10.1029/2002JA009452, 2002.

Kelley, M. C.: In situ ionospheric observations of severe weatherrelated gravity waves and associated small-scale plasma structure, J. Geophys. Res., 102, 329-335, 1997.

Kelley, M. C., Garcia, F., Makela, J., Fan, T., Mak, E., Sai, C., and Alcocer, D.: Highly structured tropical airglow and TEC signature during strong geomagnetic activity, Geophys. Res. Lett., 27, 465-468, 2000.

Maruyama, T.: A diagnostic model for equatorial spread F 1. Model description and applications to electric field and neutral wind effects, J. Geophys. Res., 93, 14 611-14 622, 1988.

Palmroth, M., Laakso, H., Fejer, B. G., and Pfaff Jr., R. F.: DE 2 observations of morningside plasma density depletions in the equatorial ionosphere, J. Geophys. Res., 105, 18 429-18 442, 2000.

Prolss, G. W. and Najita, K.: Magnetic storm associated changes in the electron content at low latitudes, J. Atmos. Terr. Phys., 37, 635-643, 1975.

Sahai, Y., Aarons, J., Mendillo, M., Baumgardner, J., Bittencourt, J. A., and Takahashi, H.: OI $630 \mathrm{~nm}$ imaging observations of equatorial plasma depletions at $16^{\circ} \mathrm{S}$ dip latitude, J. Atmos. Terr. Phys., 56, 1461-1475, 1994.

Sahai, Y., Fagundes, P. R., Bittencourt, J. A., and Abdu, M. A.: Occurrence of large scale equatorial F-region plasma depletions during geo-magnetic disturbances, J. Atmos. Sol.-Terr. Phys., 60, 1593-1604, 1998.

Sahai, Y., Fagundes, P. R., and Bittencourt, J. A.: Transequatorial Fregion ionospheric plasma bubbles: solar cycle effects, J. Atmos. Sol.-Terr. Phys., 62, 1377-1383, 2000. 
Sahai, Y., Fagundes, P. R., Abalde, J. R., Pimenta, A. A., Bittencourt, J. A., Otsuka, Y., and Rios, V. H.: Generation of largescale equatorial F-region plasma depletions during low spread-F season, Ann. Geophys., 22, 15-23, 2004.

Sekar, R. and Kelley, M. C.: On the combined effects of vertical shear and zonal electric field patterns on nonlinear equatorial spread-F evolution, J. Geophys. Res., 103, 20 735-20 747, 1998.

Senior, C. and Blanc, M.: On the control of magnetospheric convection by the spatial distribution of ionospheric conductivities, J. Geophys. Res., 89, 261-284, 1984.

Spiro, R. W., Wolf, R. A., and Fejer, B. G.: Penetration of highlatitude-electric-field effects to low latitudes during SUNDIAL 1984, Ann. Geophys., 6, 39-50, 1988.

Sultan, P. J.: Linear theory and modeling of the Rayleigh-Taylor instability leading to the occurrence of equatorial spread-F, J. Geophys. Res., 101, 26875-26891, 1996.
Tsunoda, R. T.: Control of the seasonal and longitudinal occurrence of equatorial scintillations by the longitudinal gradient in the integrated E-region Pedersen conductivity, J. Geophys. Res., 90, 447, 1985.

Valladares, C. E., Hanson, W. B., McClure, J. P., and Cragin, B. L.: Bottomside sinusoidal irregularities in the equatorial F-region, J. Geophys. Res., 88, 8025-8042, 1983.

VanZandt, T. E., Peterson, V. L., and Laird, A. R.: Electromagnetic drift of the midlatitude $\mathrm{F}_{2}$-layer during a storm, J. Geophys. Res., 76, 278-281, 1971.

Whalen, J. A.: Dependence of equatorial bubbles and bottomside spread-F on season, magnetic activity, and $\boldsymbol{E} \times \boldsymbol{B}$ drift velocity during solar maximum, J. Geophys. Res., 107, doi:10.1029/2001JA000039, 2002. 